\title{
Globalização da Internet, Soberania ou Democracia: o Trilema do Fórum de Governança da Internet*
} Globalization of the Internet, Sovereignty or Democracy: The Trilemma of the Internet Governance Forum

\author{
Peng Hwa Ang ${ }^{* * *}$ \\ Natalie Pang ${ }^{* * *}$
}

\section{RESUMO}

Propósito - À medida que as tecnologias de comunicação tornam-se cada vez mais inovadoras e a Internet cresce, fica evidente a necessidade de rever o mandato do Fórum de Governança da Internet. O propósito deste artigo, então, é baseado em

\footnotetext{
*Artigo previamente publicado em inglês na Revue française d'études américaines 134 ( $4^{\text {th }}$ trimester 2012), Paris: Publisher Belin, p. 114-127 e traduzido por André Moura Gomes, mediante autorização dos autores e da editora. Certas expressões do original foram mantidas entre colchetes no texto para o fim de maior precisão terminológica, possibilitando-se a conferência do termo original por parte do leitor. **Peng Hwa Ang é Diretor do Centro de Pesquisa sobre a Internet de Cingapura na Escola de Comunicação e Informação Wee Kim Wee, Universidade de Tecnologia Nanyang, Cingapura. Ele é autor de "Ordenando o Caos: Regulando a Internet" ["Ordering Chaos: Regulating the Internet"] (Thomson, 2005), que defende que a Internet pode, está sendo e deve ser regulada. Seus interesses de pesquisa e ensino combinam direito e comunicação, tangenciando direito e política, censura e o impacto social da mídia. Ele foi membro do Grupo de Trabalho sobre Governança da Internet "40-strong", que foi indicado pelo Secretário-Geral da ONU Kofi Annan para elaborar um relatório para a Cúpula Mundial sobre a Sociedade da Informação de 2005. Ele é cofundador da Rede Acadêmica sobre Governança Global da Internet, em que atuou como Presidente inaugural, e também auxiliou no lançamento do Fórum de Governança da Internet Regional da Ásia-Pacífico. Contato: tphang@ntu.edu.sg.

****Natalie Pang é Professora Assistente na Divisão de Estudos da Informação da Escola de Comunicação e Informação Wee Kim Wee e Pesquisadora-Chefe do Centro de Inovações de Mídia Social para Comunidades (CIMSC) [Centre of Social Media Innovations for Communities (COSMIC)]. Seus campos de pesquisa principais envolvem o estudo de efeitos da tecnologia, ação coletiva e comportamento da informação na Internet, e inovações de mídia social para comunidades marginalizadas. Ela é parte da Associação de Pesquisadores sobre a Internet e membro do Centro de Pesquisa sobre a Internet de Cingapura. Contato: NLSPANG@ntu.edu.sg.
} 
pesquisa feita sobre a globalização e a democracia (Chua, 2003), sobre os "trilemas" da globalização (Rodrik, 2000) e sobre a lógica da ação coletiva (Olson, 1971).

Metodologia/abordagem/design - Os autores usam argumentos baseados em economia, ciência política e teoria comunicação de forma a responder à seguinte pergunta: até que ponto é possível pôr em prática uma política de governança da Internet?

Resultados - Eles concluem, por um lado, que os Estados devem aderir à globalização "magra" da Internet ou escolher entre soberania e democracia.

Implicações práticas - Por outro lado, concluem que os Estados Unidos, que continuam a dominar a Internet, devem permanecer engajados e envolvidos na governança da Internet

Palavras-chave: governança da Internet, ação coletiva, integração global, globalização, FGI.

\section{ABSTRACT}

Purpose - While communication technologies become more innovative and Internet grows, the need to review the mandate of the Internet Governance Forum is clearly evident. The purpose of this article is based, then, on research done on globalization and democracy (Chua, 2003), on "trilemmas" of global integration (Rodrik, 2000) and on the logic of collective action (Olson, 1971).

Methodology/approach/design - The authors use arguments based on economics, political science and communication theory in order to answer the following question: to what extent is it possible to put into practice a policy for Internet governance?

Findings - They conclude, firstly, that States should stick to "thin" globalization of the Internet or choose between sovereignty and democracy.

Practical implications - Secondly, they also conclude that the United States, which continues to dominate the Internet, must remain engaged and involved in Internet governance.

Keywords: Internet governance, collective action, global integration, globalization, $I G F$.

\section{Introdução}

Desde o seu surgimento em 2006, como um resultado da Cúpula Mundial sobre a Sociedade da informação [World Summit on the 
Information Society], o Fórum de Governança da Internet (FGI) [Internet Governance Forum (IGF)] pretendeu ser uma plataforma para o discurso democrático sobre questões difíceis e sensíveis a respeito da maneira pela qual a Internet estava sendo dirigida e viria a ser dirigida. $\mathrm{O}$ objetivo relativamente modesto de ser um mero "talk show" foi intencional. Ainda que nunca dito publicamente, era comentado nos bastidores que um "talk show" sem poder decisório iria evitar debates demorados sobre a redação de acordos ou decisões. É possível dizer que o FGI foi bem-sucedido como um "talk show". Tanto o Secretário-Geral da ONU em uma recomendação formal à Assembleia Geral quanto seus participantes em uma pesquisa informal em 2009, de maneira geral, querem que ele permanece existindo após a avaliação quinquenal (United Nations General Assembly, 2010).

Tendo atingido esse objetivo relativamente modesto, a próxima pergunta natural é: qual será o próximo mandato do FGI? Pode o FGI ser uma plataforma não apenas para debate, mas também para ação? Até que ponto a governança da Internet pode ser internacional?

O FGI foi criado na segunda Cúpula sobre a Sociedade da Informação (CMSI) [World Summit on the Information Society (WSIS)] em 2005, a partir da recomendação do Grupo de Trabalho sobre a Governança da Internet (GTGI) [Working Group on Internet Governance (WGIG)]. O FGI tem sido bem-sucedido em reunir governos, think tanks, e acadêmicos para discutir e debater questões sobre governança da Internet, bem como perspectivas sobre com o quê a governança da Internet deveria se parecer. Os participantes representam interesses diversos e, em alguns casos, visões opostas. Então, mesmo que o seu mandato o autorize a fazer recomendações, o Fórum tem evitado fazê-lo. ${ }^{1}$

Este artigo é uma tentativa de enfrentar a seguinte pergunta: é possível, mesmo conceitualmente, que um organismo como o FGI se reúna em nível internacional para trabalhar sobre a governança da Internet? Se for

${ }^{1}$ Parágrafo 72 da Agenda de Túnis: "72. Nós solicitamos ao Secretário-Geral das Nações Unidas, em um processo inclusivo e aberto, que convoque, até o segundo trimestre de 2006, uma reunião de um novo fórum para diálogo multi-stakeholder de políticas - chamado Fórum de Governança da Internet - FGI. O mandato do Fórum é para: ( $7^{\circ}$ tópico a partir de cima) Identificar questões emergentes, levá-las à atenção dos organismos relevantes e do público em geral, e, quando apropriado, fazer recomendações." 
conceitualmente possível, então pode-se atribuir a deficiência do FGI a fatores práticos de, por exemplo, diplomacia, política e, talvez, liderança. Em contrapartida, se isso não for possível, mesmo conceitualmente, então o FGI está fadado a permanecer um "talk show", cuja atividade não deveria sequer servir como referência.

Este artigo discute as principais questões relacionadas à possibilidade de uma governança internacional da Internet, utilizando uma abordagem multidisciplinar, mediante argumentos da economia, ciência política e teoria da comunicação. São apresentados os fatores que estão conformando diuturnamente o discurso vigente sobre a governança internacional da Internet e a convergência de acordos globais.

\section{Os "Trilemas" para Alcançar a Governança Internacional da Internet}

Nos primeiros anos da Internet, a visão predominante era de que os governos poderiam ficar de fora dos diálogos sobre a governança da Internet (Baird 2002). O rápido crescimento da Internet, todavia, levou a demandas crescentes para que os governos exercessem papéis variados, tais como a regulação de cibercrimes e a assunção da responsabilidade pela garantia do acesso. Isso é um desenvolvimento inevitável, dada a importância da Internet. Em uma pesquisa global da BBC World Service de 2010 com quase 28.000 cidadãos adultos de 26 países, quatro em cinco participantes consideraram o acesso à Internet um direito humano fundamental (BBC). Tratar a Internet como um direito fundamental clama por envolvimento de governos, porque são os governos que possuem as instituições e os recursos para garantir direitos humanos.

Enquanto a maioria (53\%) daqueles consultados concordou que não deveria haver regulação da Internet "por qualquer nível de governo onde quer que seja", as respostas à pesquisa revelam maiores sutilezas conforme o país. Por exemplo, no Canadá, onde as principais preocupações com a Internet se relacionam com fraude e privacidade, a maioria (51\%) discordou da visão de que a Internet nunca deveria ser regulada. Como os canadenses, $53 \%$ dos participantes australianos apoiaram alguma forma de regulação 
governamental. Em contraste, $72 \%$ dos participantes no México disseram que a Internet não deveria ser regulada por qualquer forma de governo.

Não obstante as diferentes visões sobre regulação, existem muitas situações que pedem que governos exerçam um papel na governança da Internet. Em 2000, Joseph Gutnick, um executivo de Victoria, processou o Dow Jones \& Co Inc. por difamação com relação a um artigo no Barron's Online que o associou a negócios escusos e a relações com grupos de lavagem de dinheiro (Fitzgerald 2003). Ainda que o artigo tenha sido escrito e publicado nos Estados Unidos, a corte decidiu que, dado que a revista online contendo o artigo estava acessível em Victoria, a publicação tinha ocorrido em Victoria e, então, a lei local victoriana era aplicável. Casos como este mostram que a jurisdição do governo sobre a Internet se tornou uma necessidade. A governança da Internet reside no campo das fronteiras formadas por grupos de interesse globais e estados-nação (Goldsmith e Wu 2006).

Portanto, há uma função clara para o envolvimento significativo do governo com relação à governança da Internet no nível nacional. Mas, no nível internacional, o desenvolvimento de políticas para a governança global da Internet é muito mais difícil devido a finalidades conflitantes. Elas existem na forma de "trilemas", segundo o termo proposto por Dani Rodrik (2000), em que os países que desejam maior integração econômica em nível global não esperam alcançar todos os três objetivos de globalização, soberania nacional e democracia. Rodrik defende que, ao contrário, eles só esperam alcançar dois dos três objetivos. Mesmo que a perspectiva de Rodrik seja derivada da economia, seus argumentos não estão confinados à economia. Ele apresenta três cenários para reforçar seu argumento.

O primeiro cenário para os países que querem integração econômica global mais profunda é ir ao encontro do federalismo global, em que o escopo da política nacional está alinhado com o escopo dos mercados globais, que no presente caso seriam preocupações globais com a política. A experiência da União Europeia, no entanto, demonstra a dificuldade em alcançar o federalismo global mesmo entre países relativamente semelhantes e de orientações similares.

O segundo cenário é tornar o país sensível apenas às necessidades da economia internacional, ou, no presente caso, por analogia, à política 
internacional para a Internet. Esta é uma renúncia da soberania nacional e é incompatível com a democracia nacional. Com a Internet, é especialmente difícil, se não impossível, alcançar acordos internacionais. A razão para a dificuldade é que uma grande parte da Internet está conectada à mídia, ou contém conteúdos de mídia. Embora o princípio da liberdade de expressão contida no Artigo 19 da Declaração de Direitos Humanos da ONU tenha ampla aceitação, na prática, o direito e a política em relação a conteúdos de mídia tendem a ser específicos de cada cultura e as diferenças culturais nesse ínterim são evidentes em um conjunto de nações, fazendo, portanto, com que acordos internacionais se tornem difíceis. A situação se diferencia, por exemplo, de acordos sobre direitos de tráfego aéreo, em que as dificuldades tendem a ser de natureza mais técnica.

O terceiro cenário caminha no sentido de uma versão limitada da globalização. Rodrik defende que foi uma versão "magra" da globalização que permitiu que o regime de Bretton Woods de 1944 funcionasse bem como o fez até os anos 1970, quando os governos eram relutantes ou incapazes de agir no fluxo de capitais. Ele defende que a "[d]emocracia é compatível com a soberania nacional apenas se restringirmos a globalização" (2010).

Tem sido apontado que, com a globalização, "eventos globais podem por meio da telecomunicação, computação digital, mídia audiovisual, foguetes, e assim por diante - ocorrer quase simultaneamente em qualquer lugar e em todos os lugares no mundo" (Scholte 1996, 45). No coração da globalização está a velocidade acelerada em que as atividades ocorrem. Isto contém várias implicações: a mais aparente delas é a quebra de fronteiras geográficas ou territoriais, em que a informação é transmitida através do mundo, e indivíduos podem participar no mesmo evento ao mesmo tempo, independentemente de sua localização geográfica. $\mathrm{O}$ único requisito para participação é o acesso à Internet. Neste contexto, a globalização poderia significar que apenas uma minoria da população global se beneficia, enquanto a maioria vê-se impedida por desigualdades no acesso à Internet e insuficiência de recursos humanos ou financeiros para participar. Sendo a globalização um processo evolutivo, nações em desenvolvimento podem ainda ser desfavorecidas por sua falta de participação no seu estágio inicial, mesmo que eventualmente ganhem acesso. 
A globalização cria desafios significativos. As fronteiras tradicionais de estados-nação, em que a cooperação pode ser concebida de uma forma sustentável e controlada, é uma coisa do passado. Governos ligados entre si pelo objetivo comum de globalização podem buscar cooperar da maneira mais eficiente possível. Em contrapartida, a transparência democrática enfatiza a necessidade de participação de países em desenvolvimento, garantindo que as vozes de vários níveis da sociedade civil sejam ouvidas e permitindo o acesso a organizações sem fins lucrativos. Governos que perseguem a globalização no interesse de se manterem competitivos são inevitavelmente confrontados pela transparência democrática.

Como o trilema é resolvido? $\mathrm{Na}$ análise de Rodrik, na busca pela integração global, apenas se pode escolher dois dos três objetivos de globalização, soberania nacional e democracia.

Nossa sugestão é de que, dado que os três objetivos são desejáveis na governança internacional da Internet, duas opções são possíveis. A primeira opção é diluir um desses objetivos. Nesta opção, ainda que a globalização seja dada em razão da natureza internacional da Internet, a resolução do trilema é ter uma versão "magra" da globalização. Na governança da Internet, isto significa que, enquanto há espaço para acordos internacionais, há também grandes áreas em que os países "fazem o que bem entendem", independentemente do que os outros fizerem. Há um mecanismo de autocorreção nesta abordagem: aquelas áreas que são deixadas de fora, mas ainda têm um impacto significativo nos outros, atraem atenção cedo o bastante. Isto significa que as áreas em que os países "fazem o que bem entendem" serão áreas consideradas como tendo impacto menos significativo globalmente.

A segunda opção é abandonar um dos três objetivos. Concentrar-se na governança internacional da Internet requereria aceitar a globalização como um dado. Consequentemente, em vez de dilui-la, a escolha seria entre soberania e democracia como um objetivo. O governo norte-americano, por meio da Declaração de Compromisso (DOC) [Affirmation of Commitment $(A O C)]$, que afirma seu compromisso a, entre outras coisas, "garantir que suas decisões [...] sejam tomadas no interesse público e sejam passíveis de responsabilização e transparentes" (ICANN 2009), definiu o tom e indicou que está preparado para abrir mão de alguma soberania para a governança 
global da Internet. Isto é, a DOC escolheu, voluntariamente ou não, a democracia sobre a soberania nacional como um objetivo para a governança internacional da Internet.

Por outro lado, a tentativa do Congresso norte-americano de aprovar o Projeto Pare a Pirataria Eletrônica (PPPE) [Stop Online Piracy Act (SOPA)] é um caso de escolha da soberania sobre a democracia. Apesar de os Estados Unidos estarem agindo apenas domesticamente, em razão do alcance das companhias de Internet norte-americanas, o impacto do PPPE (SOPA) na prática teria sido global (Fahrenthold 2012). Um exemplo disso está no Acordo de Comércio Anti-Contrafação (ACAC) [AntiCounterfeiting Trade Agreement (ACTA)], pelo qual vários países liderados por Japão e Estados Unidos concordaram em fortalecer a aplicabilidade de direitos de propriedade intelectual. Como o acordo fora negociado por um grupo pequeno de países, foi principalmente um exercício da soberania nacional sobrepondo-se à democracia. No entanto, como não foi um esforço unilateral, mas envolvendo alguns países, isto também é um exemplo de globalização "magra”.

\section{Paradoxo da Globalização}

A escolha da democracia como um objetivo, seja no nível local ou no global, não ocorre sem seus problemas. Amy Chua defende de maneira convincente, ainda que novamente do ponto de vista da economia, que a globalização tem estado propensa a beneficiar uma minoria, deixando uma maioria marginalizada. Isto se deve a uma tendência dos mercados de "concentrar riqueza, frequentemente uma riqueza impressionante, nas mãos da minoria que domina o mercado" (Chua 2003, 6). A democracia, no entanto, dá o poder dos votos à maioria. Há, portanto, uma tendência de que as forças da democracia e da globalização se oponham uma à outra. Chua cita os casos dos chineses na Indonésia (onde 3\% da população que é chinesa controla $70 \%$ da economia), dos libaneses em Serra Leoa, dos judeus na Rússia pós-soviética, dos indianos no Quênia, e dos brancos no Zimbábue como exemplos em que minorias que dominam o mercado se tornaram alvo de confisco de propriedades, violência étnica e mesmo genocídio. Na Indonésia, depois da queda do Presidente Suharto, estabelecimentos chineses foram queimados e 150 mulheres chinesas 
sofreram estupro coletivo. Chua aponta: "mesmo assumindo que o livre mercado seja o ponto de chegada ótimo para a maioria dos países nãoocidentais, no curto prazo os mercados e a democracia são eles mesmos parte do problema" (Chua 2003, 278).

A solução de Chua é a introdução de amplas reformas que dariam a populações marginalizadas uma parcela dos recursos de sua nação, bem como políticas de ação afirmativa maciças. A consequência disso é o afastamento do livre mercado e da democracia, ainda que, Chua defende, no longo prazo a sociedade se volte para essa direção.

No contexto da governança da Internet, a estrutura da democracia, que empodera a maioria, requer que os governos enfrentem questões de igualdade e participação transparente, particularmente dos vários setores que compõem a sociedade civil. Isto implica que, além de interesses governamentais, tanto os setores privado quanto sem fins lucrativos precisam ser representados na conformação da governança internacional da Internet. Tal participação triangular assegura que diferentes habilidades e interesses sejam contemplados. Esta análise sugere que os governos têm de se comprometer com os processos de governança da Internet, com o objetivo de estabelecer credibilidade e transparência.

\section{A Lógica da Ação Coletiva}

No entanto, mesmo com governos compromissados, há fatores que trabalham contra o sucesso da ação coletiva em escala global. Colocada à parte a questão do "carona", em que alguns participantes tendem a se aproveitar dos esforços de outros sem ter de contribuir (Bimber et al. 2010), alguns grupos são de fato mais propensos a ter maior influência sobre as políticas de governança que outros grupos.

A teoria da ação coletiva de Mancur Olson sugere que a diversidade da Internet, a falta de uma agência de coordenação central, o problema do carona e o número elevado de governos envolvidos são fatores que podem ser contraproducentes à busca de um objetivo comum - a despeito do quão claro e explícito tal objetivo possa ser. Olson desenvolveu a teoria para desafiar a premissa de que grupos ou indivíduos unidos por interesses comuns iriam tomar ações coerentes para garantir o progresso desses 
interesses. Ele defendeu que certas condições são essenciais para que o sucesso da ação coletiva ocorra:

A não ser que o número de indivíduos seja reduzido, ou a não ser que haja coerção ou algum outro mecanismo especial para fazer indivíduos agirem no seu interesse comum, indivíduos racionais, autointeressados não agirão para alcançar seus interesses comuns ou do grupo. (Olson 1971, 2)

Trabalhos mais recentes sugerem que novas tecnologias, tal como a arquitetura de rede descentralizada da Internet, podem superar alguns dos fatores negativos, por exemplo, a falta de uma coordenação central e o problema do carona, quando aqueles que não contribuem podem ainda se beneficiar se aproveitando daqueles que contribuem. De acordo com Bruce Bimber, novas formas de ação coletiva têm emergido do ambiente de mídia contemporâneo, sugerindo que a teoria da ação coletiva de Olson pode requerer alguma reformulação. Por exemplo, a proposição de Olson de que pequenos grupos são mais propensos a realizar ações coletivas bemsucedidas que grandes grupos pode agora ser contrastada com evidências contemporâneas de redes altamente bem-sucedidas, mesmo sendo grandes e frouxamente coordenadas, como a Wikipedia e a Indymedia. A ideia do carona como contradizendo o sucesso de uma ação coletiva está se provando uma inverdade, com a participação maciça de petições online, fóruns de discussão e comunidades virtuais, em que "contribuições úteis emergem de um processo interativo, ao invés da busca explícita de um objetivo" (Bimber et al. 2006, 371).

O trabalho de Bimber ressaltou pontos importantes sobre a natureza dinâmica das tecnologias e como elas conformam a ação coletiva. Mas seu trabalho também traz de volta uma das premissas fundamentais de Olson. Olson sugeriu que um grupo poderia contribuir de maneira ótima - mesmo se o grupo não fosse pequeno - mas que essa contribuição era proporcional a quão elas fossem perceptíveis. Com a velocidade acelerada das atividades na Internet, os conceitos de tamanho do grupo e tempo podem estar mudando, e o benefício percebido de ser um colaborador para um objetivo 
comum pode explicar muito bem por que certas redes de grandes dimensões como a Wikipedia podem funcionar tão bem no contexto de hoje.

Talvez os três fatores mais importantes que têm de ser endereçados para alcançar a governança internacional da Internet sejam as questões interconectadas do carona, do papel dos Estados Unidos como um ator central e da produção de bens públicos como resultado da ação coletiva. Olson defende de maneira convincente que, quanto maior o grupo, maior a probabilidade do carona. Com a governança internacional da Internet literalmente englobando o mundo, isto significa que o problema do carona será um fator permanentemente presente. A presença de mais atores significa que os recursos e contribuições potenciais que podem ser trazidos para apoiar a governança da Internet também podem ser grandes. Estrategicamente, práticas de transparência e mecanismos para reconhecer as contribuições de todos os participantes são cruciais. Este princípio é, no entanto, acompanhado pela própria governança do bem coletivo, neste caso a governança internacional da Internet. Poderes hegemônicos no controle do bem coletivo, que desconsideram as contribuições individuais dos participantes, podem contribuir para o problema do carona.

A segunda questão importante é o envolvimento do país dominante, os Estados Unidos. O perfil demográfico dos usuários da Internet está mudando, com a China tendo superado os Estados Unidos como o país com o maior número de usuários (MacCartney 2008). A população da Internet da Índia não estará muito atrás. O papel dos Estados Unidos como uma agência de coordenação central continuaria a ser vital para a vida da Internet, não apenas por causa do seu controle técnico sobre o recurso, mas também por causa do seu compromisso com a democracia, transparência, abertura e direito humanos, contrariamente aos outros países hegemônicos que estão disputando o controle da Internet.

Em 1998, o governo dos Estados Unidos criou a Corporação da Internet para Atribuição de Nomes e Números (CIANN) [Internet Corporation for Assigned Names and Numbers (ICANN)] como uma organização sem fins lucrativos para regular todos os sistemas que podem identificar os endereços da Internet de maneira única. Tais sistemas incluem o sistema de nome de domínio [domain name system], e com esse sistema alguém poderia controlar os nomes de domínio de alto nível (i.e. .com, .org ou .net). A 
função técnica está clara, mas contém implicações importantes para a política de governança.

Várias questões têm emergido nos últimos tempos que desafiam a posição da ICANN, tais como o debate sobre o domínio de alto nível do Iraque, ".IQ" (Bull 2005). Ainda que o controle sobre o domínio tenha sido primeiramente aprovado e concedido em 1998, a ICANN tomou o controle do domínio em 2002 quando o executivo palestino Bayan Elashi, que fazia o registro do nome de domínio .IQ, foi preso (McCarthy 2004). Apesar de várias solicitações do governo recém-constituído e de líderes empresariais do Iraque para que o controle do domínio fosse liberado, a ICANN recusou a solicitação e concedeu o nome de domínio .IQ somente quando o Grupo de Trabalho sobre Governança da Internet (GTGI) [Working Group on Internet Governance (WGIG)] estava para emitir seu Relatório Final, que iria, implicitamente, criticar sua retenção. A ICANN disse que era necessário reter o retorno do nome de domínio .IQ porque o governo do Iraque não seria estável (Mayer-Schoenberger e Ziewitz 2006). De toda forma, tais ações são indubitavelmente percebidas como contraditórias à sua perspectiva de transparência e abertura.

Dados os debates em andamento sobre a ICANN e a atual crise financeira nos Estados Unidos, a pergunta que se coloca é se o seu compromisso à governança internacional da Internet está tão forte quanto antes. Isto pode ser difícil de atingir em face de "patriotas ignorantes" (Schaar 1981, 302) que não veem bens coletivos globais como seus bens.

Mesmo com o entendimento comum e o desejo de produzir bens coletivos globais, tal produção e uso de bens coletivos globais pode não ser sustentável. Na análise de Olson, não seria racional para qualquer um contribuir com o coletivo se for possível ter uma carona grátis. De fato, há muitos aproveitadores - aqueles que veem, mas não postam - em listas de e-mail, com um post famoso de um colunista online estimando-os em 98\% (Katz 1998), ainda que uma tese de doutorado posterior e mais minuciosa tenha chegado a 55\% (Nonnecke 2000). Todavia, como sítios eletrônicos como a Wikipedia mostram, voluntários colaboram, sim, por várias razões não-monetárias, tais como retorno positivo e identificação com a comunidade (Schroder e Hertel 2009). 
Na visão de Olson, a ação coletiva seria em sua maior parte racional, sugerindo que há condições necessárias para que seres racionais participem. Tais condições incluem coerção, com participantes sendo "forçados" ou obrigados a participar por meio de normas institucionais ou sanções. Quando tais condições estão presentes, a ação coletiva pode ser possível, mas ainda seria difícil implementá-la em grupos intermediários ou grandes. Olson não visualizou, contudo, que grandes grupos e instituições podem realizar ações coletivas bem-sucedidas sem sanções. O trabalho de Ostrom preencheu essa lacuna, mostrando exemplos de comunidades auto-geridas que criaram instituições para a ação coletiva. Mueller defende que o caso da governança da Internet é essencialmente uma história de "inovação institucional” (Mueller 2002, 10). Isto lança mais luz sobre o papel do FGI em desenvolver arranjos institucionais e endereçar os desafios da governança da Internet.

Gerald Marwell e Pamela Oliver, testando e desenvolvendo as ideias de Olson, demonstram de maneira bem convincente que, para atingir sustentabilidade, precisa-se de uma massa crítica de participantes. Sem essa massa crítica, a empreitada irá provavelmente falhar. Para a governança da Internet, isto implica ter uma massa crítica de participantes representando diversos setores e que interesses públicos contribuam com bens globais e coletivos para a comunidade internacional. Em outras palavras, usuários da Internet podem ser tornar relevantes na colaboração ou desestabilização da causa da governança da Internet. A partir daqui, três cenários postulados por Marwell e Oliver podem ser construídos usando a sua teoria micro-social da massa crítica na ação coletiva.

No primeiro cenário, os participantes são fortemente coesos; as contribuições são claramente coordenadas e podem ser perceptivelmente reconhecidas por seus efeitos acelerados e incrementais no bem coletivo. Neste cenário, o carona não é um problema e os participantes são inspirados pelas contribuições de outros. Há, no entanto, custos iniciais e de organização consideráveis - e a massa crítica neste cenário são aqueles que suportam o peso desses custos para viabilizar a participação voluntária maciça. A dificuldade neste cenário é mais proeminente na fase inicial, em que nenhum participante enxerga qualquer benefício em colaborar, já que os benefícios para os colaboradores iniciais pode ser insignificante. Este 
cenário é também difícil, dada a diversidade dos usuários da Internet além dos envolvidos na governança da Internet, e pode ser difícil sintetizar opiniões.

No segundo cenário, há apenas alguns atores que contribuem por muitos. Isto é semelhante ao princípio de Pareto da regra de 80-20, e é plausível que o carona emerja em razão do que Marwell e Oliver se referem como "efeitos da ordem" ["order effects"] e "excedente" ["surplus"]. Nos "efeitos da ordem", "membros menos interessados pegam carona nas contribuições iniciais dos mais interessados, e as contribuições totais do grupo são subótimas" (Marwell e Oliver 1993, 82). O mecanismo do excedente descreve cenário em que o carona pode ocorrer quando o número de participantes comprometidos em contribuir com o bem coletivo decresce frente ao aumento no número total de participantes. Isto implica que um excedente de participantes será criado e os participantes iniciais "(...) que se deparam com a decisão [de colaborar] ficam 'paralisados'." "Eles vão contribuir porque eles consideram recompensador fazê-lo, enquanto aqueles cuja vez de decidir aparece depois vão pegar carona" (Marwell e Oliver 1993, 85). A massa crítica neste cenário se refere aos poucos que estão contribuindo com o bem coletivo de muitos. Neste cenário, Marwell e Oliver argumentam que a recompensa é decrescente. O cenário implica que nem todos os usuários da Internet podem se envolver; talvez alguns serão selecionados para agir como representantes de outros.

O último cenário é uma combinação dos dois primeiros cenários. Neste cenário, o problema de ter uma massa crítica para suportar os custos iniciais de começar é primeiro apresentado e, a não ser que tal massa crítica seja encontrada, a ação coletiva pode não ocorrer. Antes de entrar no segundo cenário, em que as recompensas decrescem, a ação coletiva pode experimentar a linearidade, em que se torna racional "todos contribuírem ou nenhum contribuir" (Oliver et al. 1985, 533).

Muitos estudiosos defendem que o último cenário é o mais realista, e as lições deste cenário podem ajudar a enfrentar os problemas antecipados. $\mathrm{O}$ estabelecimento do FGI significa que a massa crítica para começar já existe. O desafio futuro é que todos os participantes se recomprometam com a causa e lidem com o problema das recompensas marginais decrescentes, já que o número de participantes aumenta. A participação de governos irá 
provavelmente aumentar porque a União Internacional de Telecomunicações (UIT) [International Telecommunication Union (ITU)], que havia exercido um papel-chave em começar o processo que eventualmente levou à criação do Fórum de Governança da Internet, tem tentado engajar seus membros na governança da Internet. A reunião de dezembro de 2012 da UIT em Dubai reuniu diplomatas de 193 governos e há expectativa de reuniões periódicas semelhantes no futuro. A reunião de dezembro, no entanto, terminou mal-sucedida em conseguir que os membros participantes assinassem um novo tratado, com políticas sobre como a Internet deveria ser governada como ponto principal de disputa. Embora a UIT já tenha organizado com sucesso uma reunião de paísesmembros interessados, as recompensas podem decrescer como demonstrado na fragilidade de manter-se o momentum, bem assim na dificuldade prática de se alcançarem acordos.

\section{Conclusão}

A partir da análise acima, para que a governança internacional da Internet funcione, é necessária a conjugação de dois acontecimentos. Primeiro, os governos têm de se contentar com a globalização "magra" da Internet, ou escolher entre soberania e democracia. Em segundo lugar, é necessário que o país ainda dominante na Internet, os Estados Unidos, mantenham-se comprometidos e envolvidos com a governança da Internet a despeito de sua crise econômica atual.

Há múltiplos desafios à tarefa. A tensão entre as consequências da globalização e da democracia precisam ser reconhecidas. Chua defende a viabilidade de amplas reformas e políticas de ação afirmativa para dar a certas populações uma parcela dos recursos naturais nacionais. Aplicado ao contexto da governança da Internet, a estrutura da democracia e uma globalização "magra" da Internet criam um conflito similar. Enquanto uma minoria irá contribuir como voz poderosa na conformação da governança da Internet, a estrutura da democracia obriga os governos a enfrentar a questão da participação equitativa de vários setores da sociedade civil.

Isto inevitavelmente levanta o tema da ação coletiva, que foi analisado usando a teoria da ação coletiva como originalmente concebida por Olson e 
revista por outros teóricos contemporâneos, tais como Bimber et al. Para uma ação coletiva sustentável no contexto da governança internacional da Internet, o discurso sobre os bens coletivos globais - que forma eles assumirão, como os participantes poderão contribuir, e como eles poderão ser usados para o benefício de todos os atores - é importante.

A criação do FGI mostra que a massa crítica dos atores já existe em direção ao objetivo da governança internacional da Internet. Mas o cenário de recompensas marginais decrescentes, em que seria racional "todos contribuírem, ou ninguém contribuir” (Oliver et al. 1985, 533), é real. A tarefa adiante é fazer os participantes reconhecerem suas funções no FGI, enquanto são articulados mecanismos pelos quais os participantes podem contribuir. Adicionalmente, contribuições aos bens coletivos acordados deveriam também ser suficientemente visíveis, de forma que se torne mais racional contribuir ao invés de pegar carona. Alguns desses mecanismos já estão endereçados nas práticas existentes do FGI, tais como as convocações abertas para contribuir que são anunciadas e a viabilização da participação remota. Como o número de participantes e interessados aumenta, no entanto, há uma complexidade maior nas diferentes maneiras pelas quais os participantes podem colaborar e em como tais contribuições podem ser tornadas visíveis, do que decorre a necessidade de uma análise cuidadosa.

$\mathrm{O}$ artigo utilizou três argumentos centrais da economia, ciência política e teoria da comunicação para avaliar a possibilidade da governança da Internet em uma escala internacional. A análise serve para triangular perspectivas sobre a questão, bem como fornecer um raio-x dos desafios impeditivos a serem endereçados à medida que a adoção e uso da Internet cresce. A abordagem foi intencional, já que a história da governança da Internet é multifacetada. Como ocorre com muitas formas de bens coletivos, a governança não pode ser bem-sucedida por meio das forças do Estado político ou do mercado. O trabalho de Ostrom tem sido útil para ressaltar a importância de instituições dirigidas à ação coletiva para resolver os problemas da governança da Internet. Com o aumento da penetração da Internet em nível global, espera-se um aumento da complexidade da governança da Internet e o FGI precisará considerar novos arranjos institucionais ou reformas de forma a alcançar uma ação coletiva bemsucedida. 


\section{Bibliografia}

CHUA, Amy. World On Fire: How Exporting Free Market Democracy Breeds Ethnic Hatred and Global Instability. New York: Doubleday, 2003.

BAIRD, Zoe. Governing the Internet: Engaging government, business, and nonprofits. In: Foreign Policy 19: 6 (2002): 15-20.

$\mathrm{BBC}$. Internet access is 'a fundamental right'. BBC Technology News, 8 Março de 2010.

BIMBER, Bruce, FLANAGIN, Andrew J. e STOHL, Cynthia. Reconceptualizing Collective Action in the Contemporary Media Environment. In: Communication Theory 15: 4 (2006): 365-388.

BULL, Bartle Breeze. The 'iq' debacle. In: Foreign Policy 1 (2005): 109.

FAHRENTHOLD, David A. SOPA Protests to Shut Down Web Sites. The Washington Post. 17 de janeiro de 2012.

FITZGERALD, Brian. Dow Jones \& Co Inc v Gutnick: Negotiating "American Legal Hegemony" in the Transnational World of Cyber Space. In: Melbourne University Law Review 21 (2003).

GOLDSMITH, Jack e WU, Tim. Who Controls the Internet? Illusions of a Borderless World. Oxford: Oxford UP, 2006.

HELLER, Michael. The Tragedy of the Anticommons: Property in the Transition from Marx to Markets. In: Harvard Law Review 111 (1998): 621-688.

ICANN. Affirmation of Commitments by the United States Department of Commerce and the Internet Corporation for Assigned Names and Numbers. ICANN, 30 de setembro de 2009.

JESDANUN, Anick. Internet Agency Grants Iraq the Right to Manage Its Own Domain Name: iq. Associated Press and New York Sun, 8 de agosto de 2005.

KATZ, Jon. Luring the Lurkers. Slashdot, 29 de dezembro de 1998.

MARWELL, Gerald e OLIVER, Pamela. The Critical Mass in Collective Action. New York: Cambridge UP, 1993.

MACCARTNEY, Jane. China overtakes US as world's biggest user of Internet. The Sunday Times, 25 de abril de 2008.

MAYER-SCHOENBERGER, Viktor e ZIEWITZ, Malte. Jefferson Rebuffed - The United States and the Future of Internet Governance. 
Kennedy School of Government, Harvard University, Faculty Research Working Paper Series, 2006.

MCCARTHY, Kieren. Iraq domain owner convicted: Bayan Elashi and his four brothers face 10 years in US jail. The Register, 9 de julho de 2004.

MUELLER, Milton. Ruling the Root: Internet Governance and the Taming of Cyberspace. Cambridge: MIT Press, 2002.

NONNECKE, Robert Blair. Lurking In Email-Based Discussion Lists. Ph.D. dissertation, Department of Computer Science, Southern Bank University, 2000.

OLIVER, Pamela, MARWELL, Gerald e TEIXEIRA, Ruy. A Theory of the Critical Mass, Interdependence, Group Heterogeneity, and the Production of Collective Goods. In: American Journal of Sociology 91 (1985): 522556.

OLSON, Mancur. The Logic of Collective Action: Public Goods and the Theory of Groups. $2^{\mathrm{a}}$ ed., Boston: Harvard UP, 1971.

OSTROM, E. Governing the Commons: The Evolution of Institutions for Collective Action. Cambridge: Cambridge UP, 1990.

RODRIK, Dani. Greek Lessons for the World. Project Syndicate, 11 de maio de 2010.

. How Far Will International Economic Integration Go? In: Journal of Economic Perspectives 14: 1 (2000): 177-186.

SCHAAR, John H. Legitimacy in the Modern State. New Brunswick: Transaction Publishers, 1981.

SCHOLTE, Jan Aart. Beyond the Buzzword: Towards a Critical Theory of Globalization. In: Eleonore Kofman e Gillian Youngs (org.). Globalization: Theory and Practice. London: Pinter, 1996, p. 43-57.

SCHRODER, Joachim e HERTEL, Guido. Voluntary Engagement in an Open Web-Based Encyclopedia: Wikipedians and Why They Do It. In: Media Psychology 12 (2009): 96-120.

UNITED NATIONS GENERAL ASSEMBLY. Continuation of the Internet Governance Forum: Note by the Secretary-General, Economic and Social Council, 7 de maio de 2010.

WORKING GROUP ON INTERNET GOVERNANCE. Report of the Working Group on Internet Governance. WGIG, junho de 2005. 